\title{
Optimization of microwave-assisted extraction technique for isolation of betulinic acid from Dillenia indica Linn. and its quantification using developed HPTLC method
}

\author{
Dipal Mahendrabhai Gandhi ${ }^{*}$, Harshal Patel ${ }^{2}$, Nrupesh Patel ${ }^{2}$, Priti Mehta ${ }^{2}$ \\ ${ }^{1}$ Department of Pharmacognosy, Institute of Pharmacy, Nirma University, Ahmedabad, India. \\ ${ }^{2}$ Department of Pharmaceutical Analysis, Institute of Pharmacy, Nirma University, Ahmedabad, India.
}

\begin{tabular}{|c|c|}
\hline ARTICLE INFO & ABSTRACT \\
\hline $\begin{array}{l}\text { Received on: } 01 / 04 / 2019 \\
\text { Accepted on: } 27 / 06 / 2019 \\
\text { Available online: } 03 / 08 / 2019\end{array}$ & $\begin{array}{l}\text { Modern extraction technique was investigated for the separation of betulinic acid from the bark of Dillenia indica } \\
\text { Linn. Betulinic acid, a pentacyclic triterpenoid, is a potent anticancer compound and possesses other pharmacological } \\
\text { actions. The objective of the present study was to investigate the optimum extraction conditions for betulinic acid } \\
\text { using microwave-assisted extraction by applying response surface methodology based on three factors three levels }\end{array}$ \\
\hline $\begin{array}{l}\text { Key words: } \\
\text { Betulinic acid, } \\
\text { Microwave-assisted } \\
\text { extraction, Response surface } \\
\text { methodology, } \\
\text { High-performance thin layer } \\
\text { chromatography. }\end{array}$ & $\begin{array}{l}\text { Box-Behnken experimental design. The extraction was performed by considering three different independent variables: } \\
\text { extraction temperature }\left(70^{\circ} \mathrm{C}-90^{\circ} \mathrm{C}\right) \text {, microwave power }(100 \mathrm{~W}) \text {, and extraction time }(10-20 \text { minutes }) \text { and quantified } \\
\text { using developed High-performance thin layer chromatography method. The maximum yield of betulinic acid at optimized } \\
\text { experimental conditions, i.e., } 90^{\circ} \mathrm{C}, 200 \mathrm{~W}, 15 \text { minutes was found to be } 0.91 \% \mathrm{w} / \mathrm{w} \text {. Analysis of variance showed that the } \\
\text { " } p \text {-value" was } 0.0004 \text { which indicate that the models were statistically significant }(p<0.05) \text {. The value of the "coefficient } \\
\text { of determination" }\left(R^{2}\right) \text { for microwave-assisted extraction was } 0.94 \text { which indicate that the model shows the goodness of } \\
\text { fit. To conclude, Microwave Extraction technique along with response surface design proved to be efficient compared to } \\
\text { conventional methods which could be applied to isolate active constituents from plant sources. }\end{array}$ \\
\hline
\end{tabular}

\section{INTRODUCTION}

Soxhlet extraction, continuous shaking extraction, liquid-liquid extraction, and high-speed counter-current chromatography methods were reported for isolation of many phytoconstituents from various plant species (Gandhi and Mehta, 2013a; Galgon et al., 1999; Pai et al., 2011). Conventional methods are lengthy and time-consuming; thus, advanced extraction techniques, such as supercritical fluids, ultrasound waves, pressurized liquids, microwaves, and electric field should be approached and encouraged for better extraction of phytoconstituents. Currently, microwave-assisted extraction (MAE) technique has been successfully applied for isolation of

"Corresponding Author

Dipal Mahendrabhai Gandhi, Department of Pharmacognosy, Institute of Pharmacy, Nirma University, Ahmedabad, India.

E-mail:drdipal.rx@gmail.com bioactives from various plant sources. MAE has emerged as an efficient method for the extraction of valuable compounds from different biomasses, it is a closed system and main advantages are that it can reduce extraction time with less solvent and better target extract quality with lower cost (Belwal et al., 2018; Deng et al., 2019; Domingues et al., 2013; Gava et al., 2012; Mandal et al., 2007; Sladkova et al, 2018).

It is necessary to optimize the conditions of experimental parameters and strategy of designing to design an experimental technique with efficient working (Tatke and Jaiswal, 2011). This technique can be successfully implemented to carry out a detailed experimental with the objective of analyzing the effect of MAE considering different operating conditions which may affect the yield of Betulinic acid (BA) from Dillenia indica bark, using design of experiment (DOE) followed by response surface methodology (RSM) to establish validated response functions. RSM is a combination of statistical and mathematical technique for optimizing the method, developing, improving which can increase the quantity of phytoconstituent by using different parameters. In 
order to examine the relationship between one or more response variables and different quantitative experimental parameters, Box-Behnken design (BBD) can be used (Daneshvand et al., 2012; Ferreira et al., 2007; Liu et al., 2011).

Dillenia indica Linn (D. indica) is commonly known as "Karmal" belonging to family Dilleniaceae. It is distributed in many forest regions of India, especially Madhya Pradesh, Gujarat, and South India. This plant has been used by tribal communities to cure of many diseases and disorders, such as cancer and wound healing (Kumar et al., 2010). BA is found to be present as an active phytoconstituent in $D$. indica bark, which is chemically ((3ß)-3-Hydroxylup-20(29)-en-28-oic acid). BA is a lupane type pentacyclic triterpenoids and derives its name from the white birch bark, Betula pubescent, but it can be also isolated from the leaves, roots, and bark of other plants (Muhit et al., 2010). The birch tree is the good source of betulin and its derivatives where both BA and betulin are present in substantial quantities. Since last two decades, many anti-cancer compounds were isolated from natural sources, BA is one of them having a number of pharmacological activities, such as anthelminthic, anti-tumor, antiviral, anti-HIV, antibacterial, anti-inflammatory, anti-oxidant, hepato-protective, anxiolytic, anti-malarial, and hair protecting. BA is found to be effective against different types of cancers, such as head and neck squamous carcinoma, leukemia, breast, lung, colon, ovary, and cervix (Cristina et al., 2012; Cichewicz et al., 2004; Gandhi and Mehta, 2013b; Habiyaremye et al., 2002; Moghaddam et al., 2012; Mullauer et al., 2010).

In present research work, the extraction of betulinic acid is carried out using microwave-assisted technique, number of factors affect the yield of phytoconstituent, thus to reduce number of experiments Box-benken design is used. Various optimization methods along with several crucial parameters affect the extraction efficiency are discussed here that can be applied to a process to obtain the better yield of betulinic acid from the bark of $D$. indica.

\section{MATERIALS AND METHODS}

\section{Collection and authentication of sample}

The bark of $D$. indica was collected from Waghai botanical garden of Dang district, Gujarat, India. Collected bark sample was authenticated by botanist Dr. Jasrai, School of Botany, Gujarat University, Gujarat, India. Collected bark was dried under the shade for about 10 days and was powdered using pulverizer further passed through a 60\# sieve. The prepared sample was used further for extraction and analysis.

\section{Chemicals and reagents}

Standard BA (99 \% purity) was purchased from SigmaAldrich (India), High Pressure Liquid Chromatography grade methanol and analytical reagent grade methanol, acetic acid, sulfuric acid, and Thin Layer Chromatographic (TLC) plates precoated with silica gel $60 \mathrm{~F}_{254}(20 \times 20 \mathrm{~cm}, 0.2 \mathrm{~mm}$ Layer thickness $)$ were purchased from E Merck Ltd (Darmstadt, Germany).

\section{Design of experiment and RSM}

RSM statistically gives the interaction effect between each experimental factor. RSM can be used for optimization purpose which analyze the relationship between measured responses (dependent variable) and factors (independent variable) and allow to minimize the number of experiments. BBD is a rotatable second-order multivariate design based on a three-level incomplete factorial design.

In the present work, the influences of three independent variables were studied: extraction temperature (A), microwave power (B), and extraction time (C) (Table 1) for MAE which has been evaluated for the extraction yield of BA using an experimental design. The remaining independent variables, such as particle size of bark powder and solvent, were kept constant during the experiment.

Design of a total of 15 experimental runs has been carried out using the method. The coded value and experimental design of independent and dependent variables are listed in Table 1 for MAE. Design-Expert 8, the software was used for the analysis of the results. In order to investigate the main factors and its interaction effect on percentage yield of BA, the RSM concept and DOEs was applied to evaluate factor variation and their ranges. The actual relationship between the independent and dependent variables can be represented by the analysis of variance (ANOVA) result which indicates that this model is highly significant and the $p$-value was checked. The coefficient of determination $\left(R^{2}\right)$ and their adjusted values, $R_{\text {adj }}^{2}$, were used to check the goodness of fit of the regression models. The determination coefficient, $R^{2}$, and their adjusted values, $R_{\text {adj }}^{2}$, were employed to assess the goodness of fit of the regression models.

\section{MAE and purification of BA}

MAE experiments were performed using microwave extractor (Synthos 3000, Anton Paar). Dillenia indica bark powder $(5 \mathrm{mg})$ was weighed and carefully transferred into a Wheaton vial. For each experimental run, such 20 vials were filled with bark powder. Methanol was used as an extracting solvent. The vials were sealed with a Teflon cap and tightened using a PEEK screw cap. Vials were placed into microwave extractor. Effect of three different parameters, such as extraction temperature, microwave power, and extraction time, were studied wherein total extraction yield, the yield of extract containing BA as well as the actual amount of BA in extract (Table 2). The extracts from all 20 vials were collected and volume was reduced to get approx. $10 \mathrm{ml}$ in a vacuum oven at $65^{\circ} \mathrm{C}$. The concentrated extract was analyzed and quantified using reported High-performance thin layer chromatography (HPTLC) method (Gandhi and Mehta, 2013b).

Table 1. Levels of independent and dependent variables for BBD in extraction of BA using MAE.

\begin{tabular}{cccc}
\hline & \multicolumn{3}{c}{ Levels } \\
\cline { 2 - 4 } & Low (-1) & Medium (0) & High (1) \\
\hline $\begin{array}{l}\text { Independent variables } \\
A=\text { Extraction temperature }\left({ }^{\circ} \mathrm{C}\right)\end{array}$ & 70 & 80 & 90 \\
$B=$ Microwave power $(\mathrm{W})$ & 100 & 150 & 200 \\
$C=$ Extraction time (minute) & 10 & 15 & 20 \\
$\begin{array}{l}\text { Dependent variables } \\
Y 2=\text { Percentage yield of BA }\end{array}$ & & & \\
$(\%$, wt.)
\end{tabular}


All the fractions were combined into a beaker and concentrated on a boiling water bath until the semisolid mass is obtained. The semisolid yellowish mass was washed with methanol three times. After washing, the residue was kept in a refrigerator for 2 days. The white crystalline compound was obtained which was taken further for analysis.

\section{Identification of isolated BA using FT-IR}

The isolated crystals obtained using MAE were checked and confirmed using Fourier Transform Infrared (FT-IR) method. A dried spectroscopic grade Potassium Bromide $(\mathrm{KBr})$ powder was taken and triturate it. $\mathrm{A} \mathrm{KBr}$ spectrum as a blank was taken. The isolated BA was mixed with standard spectroscopic grade $\mathrm{KBr}$ powder in a 1:100 ratio and their spectra were taken.

\section{Quantification of BA in MAE fractions using reported HPTLC method}

Ten microliter volume of collected MAE fractions and standard BA $(100 \mu \mathrm{g} / \mathrm{ml})$ was applied on the TLC plate. Plates were analyzed and the yield of BA from the collected fractions was calculated as per reported HPTLC method (Gandhi and Mehta, 2013b).

\section{RESULTS AND DISCUSSION}

In recently published work, 237 bioactive compounds were identified in the bark and these compounds were polyphenols with different active principles such as antioxidants, antibacterial etc. (Sladkova et al., 2018). BA present in bark of D. indica was extracted using modern extraction technique in order to get good yield. The structure of BA (Fig. 1) depicts that it has good solubility in a polar solvent. Hence, using methanol a solvent was essential to enhance the extraction process which simultaneously increasing the amount of BA. Content of BA was studied in parallel based on $3^{3}$ factorial DOE, special total extraction yield, the yield of extract containing BA, as well as an amount of BA in the extract.

Table 2. Design matrix and responses for BBD in MAE and \% yield of BA in each experimental run (most appropriate extraction parameters to get maximum yield).

\begin{tabular}{cccccccc}
\hline $\begin{array}{c}\text { Batch } \\
\text { No. }\end{array}$ & $\boldsymbol{A}$ & $\boldsymbol{B}$ & $\boldsymbol{C}$ & $\begin{array}{c}\text { Extraction } \\
\text { temperature } \\
\left({ }^{\circ} \mathbf{C}\right)\end{array}$ & $\begin{array}{c}\text { Microwave } \\
\text { power }(\mathbf{W})\end{array}$ & $\begin{array}{c}\text { Extraction } \\
\text { time } \\
(\text { minute) }\end{array}$ & $\begin{array}{c}\boldsymbol{Y}_{2} \\
(\% \mathbf{W t})\end{array}$ \\
\hline 1 & 0 & -1 & -1 & 80 & 100 & 10 & 0.63 \\
2 & 0 & 0 & 0 & 80 & 150 & 15 & 0.66 \\
3 & 1 & 1 & 0 & 90 & 200 & 15 & 0.71 \\
$\mathbf{4}$ & $\mathbf{1}$ & $-\mathbf{1}$ & $\mathbf{0}$ & $\mathbf{9 0}$ & $\mathbf{1 0 0}$ & $\mathbf{1 5}$ & $\mathbf{0 . 9 1}$ \\
5 & 0 & -1 & 1 & 80 & 100 & 20 & 0.61 \\
6 & -1 & 0 & -1 & 70 & 150 & 10 & 0.55 \\
7 & -1 & 1 & 0 & 70 & 200 & 15 & 0.52 \\
8 & 0 & 0 & 0 & 80 & 150 & 15 & 0.66 \\
9 & 0 & 1 & -1 & 80 & 200 & 10 & 0.57 \\
10 & -1 & -1 & 0 & 70 & 100 & 15 & 0.57 \\
11 & 0 & 0 & 0 & 80 & 150 & 15 & 0.66 \\
12 & -1 & 0 & 1 & 70 & 150 & 20 & 0.53 \\
13 & 0 & 1 & 1 & 80 & 200 & 20 & 0.56 \\
14 & 1 & 0 & 1 & 90 & 150 & 20 & 0.8 \\
15 & 1 & 0 & -1 & 90 & 150 & 10 & 0.83 \\
\hline
\end{tabular}

\section{Optimization of experimental conditions for MAE}

The extraction process of BA from $D$. indica bark was done for 15 runs as per the experimental design (Tables 1 and 2). The optimized condition was selected which gives the maximum percentage yield of BA.

The response surface plot, the contour, and overlay plots reveal the effect of the independent variables: extraction temperature and microwave power on BA content with MAE (Fig. 2a-c). The response surface plot, the contour, and overlay plots show the effect of extraction temperature and extraction time on percentage yield of BA (Fig. 3a-c). The response surface and contour plots show the effect of microwave power and extraction time on percentage yield of BA (Fig. $4 \mathrm{a}$ and b).

The effects of parameters were analyzed, and an equation was obtained from the results of experimental design as follows:

$\begin{aligned} \mathrm{Y}_{\text {Betulinic acid }}= & 0.66+0.14 * A-0.045 * B-1.00 * C-0.038 * A * B-2.50 * A * C+ \\ & 2.50 * B * C+0.051 * A^{2}-0.034 * B^{2}-0.038 * C{ }^{2} \ldots \ldots \ldots \ldots \text { Equation } 1\end{aligned}$

where $Y$ is the percentage yield of BA and $A, B$, and $C$ are the coded values of independent variables.

In order to investigate the main factors and its interaction effect on percentage yield of BA, the RSM concept and DOEs were applied to evaluate factor variation and their ranges. ANOVA showed that the " $p$-value" was 0.0004 which indicate that the model was statistically significant $(p<0.05)$. The value of the "coefficient of determination" $\left(R^{2}\right)$ was 0.99 which indicate that the models show the goodness of fit.

Based on the experimental factorial design, we concluded that the extraction temperature, microwave power, and extraction time showed a complex effect on the extraction yield. After considering all the parameters, the following extraction conditions optimized for MAE: extraction temperature, microwave power (W), and extraction time (minute) were $90^{\circ} \mathrm{C} / 100 \mathrm{~W} / 15$ minutes, respectively. The maximum percentage yield of $\mathrm{BA}$ obtained by MAE using optimized conditions from the bark sample was $0.91 \%$ (Table 2). Minimum interference of other components was observed when the bark is extracted using MAE, thus it is also more comfortable method as compared to other conventional methods which can easily be transferred from lab-scale to industry and more sustainable.

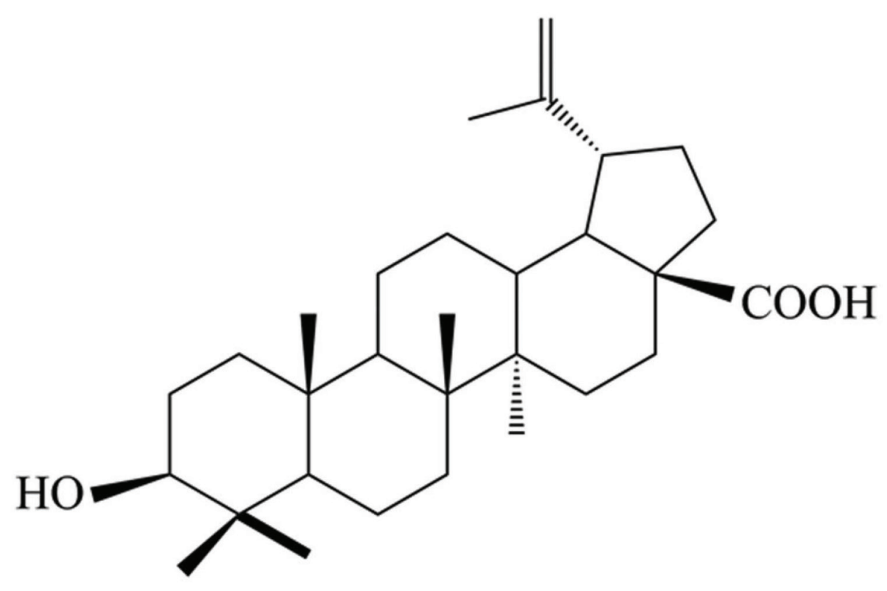

Figure 1. Chemical structure of BA. 


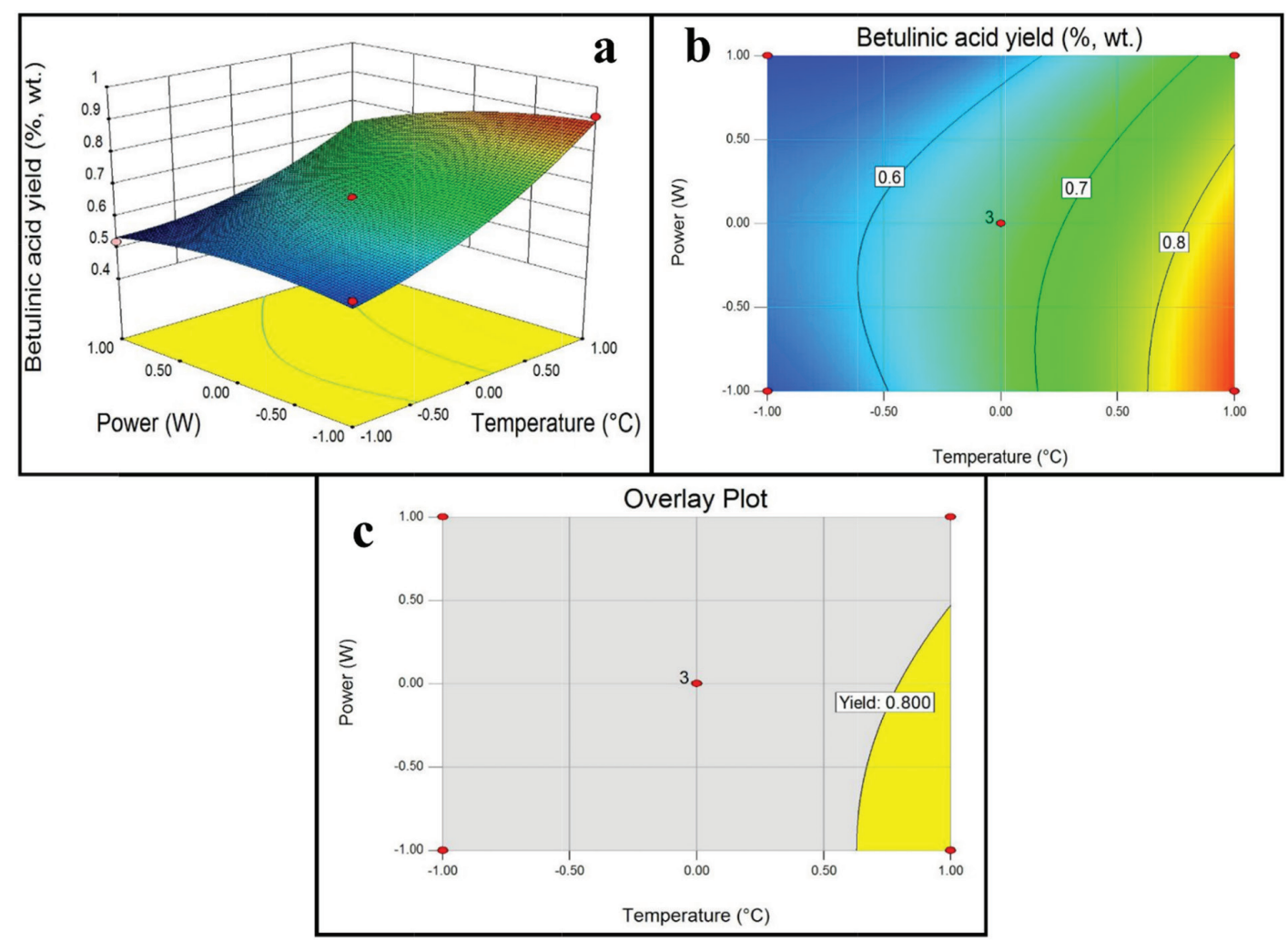

Figure 2. Effect of extraction temperature and microwave power on percentage yield of BA by MAE. (a) Response surface plot, (b) Contour plot, and (c) Overlay plot.

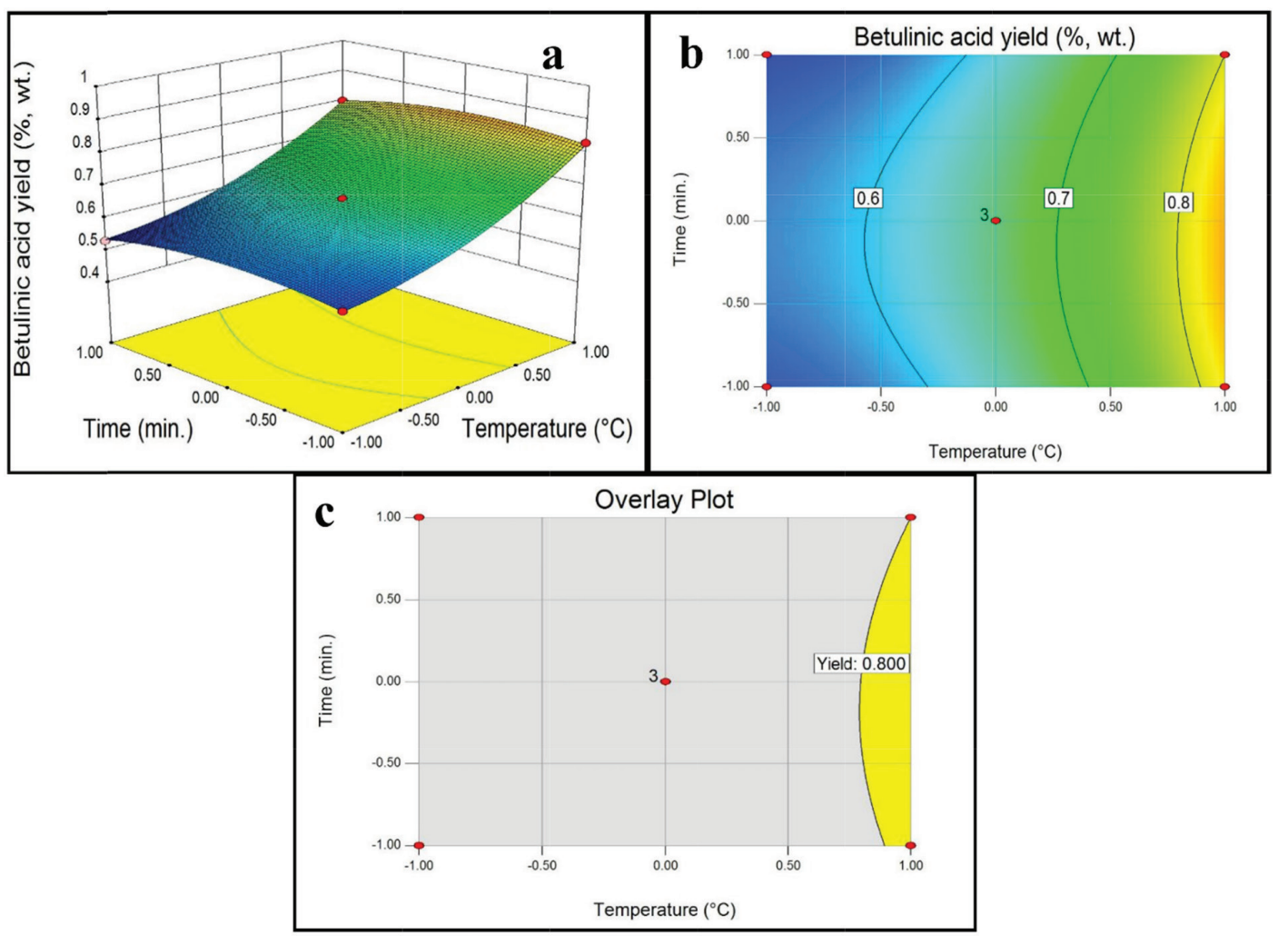

Figure 3. Effect of extraction temperature and extraction time on percentage yield of BA by MAE. (a) Response surface plot, (b) Contour plot, and (c) Overlay plot. 


\section{MAE of betulinic acid from the bark of Dillenia indica}

Collected fractions from 20 vials were combined and have been analyzed using the developed HPTLC method. Each fraction of MAE was analyzed using the reported HPTLC method. HPTLC Chromatogram of fractions collected using MAE was compared with standard betulinic acid chromatogram procured from Sigma Aldrich (Figs. 5 and 6). Derivatized HPTLC plate of collected fractions using microwave-assisted extraction of betulinic acid from the bark of $D$. indica at different optimized conditions is shown in Figure 7.

\section{Effect of extraction parameters on yield using MAE technique}

Three different factors were analyzed to get a good amount of betulinic acid from the bark powder. Increase in the temperature of microwave along with microwave power gives better yield as high power leads to rise in the temperature, thus both parameters are interrelated.

\section{Effect of temperature on extraction yield}

Increase in the temperature leads to an increase in the vapor pressure in the closed system which improves extraction efficiency since desorption of chemical constituents from the sample matrix was facilitated. The temperature rise decreases the surface tension and viscosity of a solvent which improves the sample wetting and penetration power of the solvent, respectively. The release of solute from the active site of matrix increases with the rise in temperature which results in better extraction efficiency (Eskilsson, 2000). The energy from microwave power provided to the plant matrix converted into heat energy in the dielectric material and thus temperature can be controlled (Khajeh

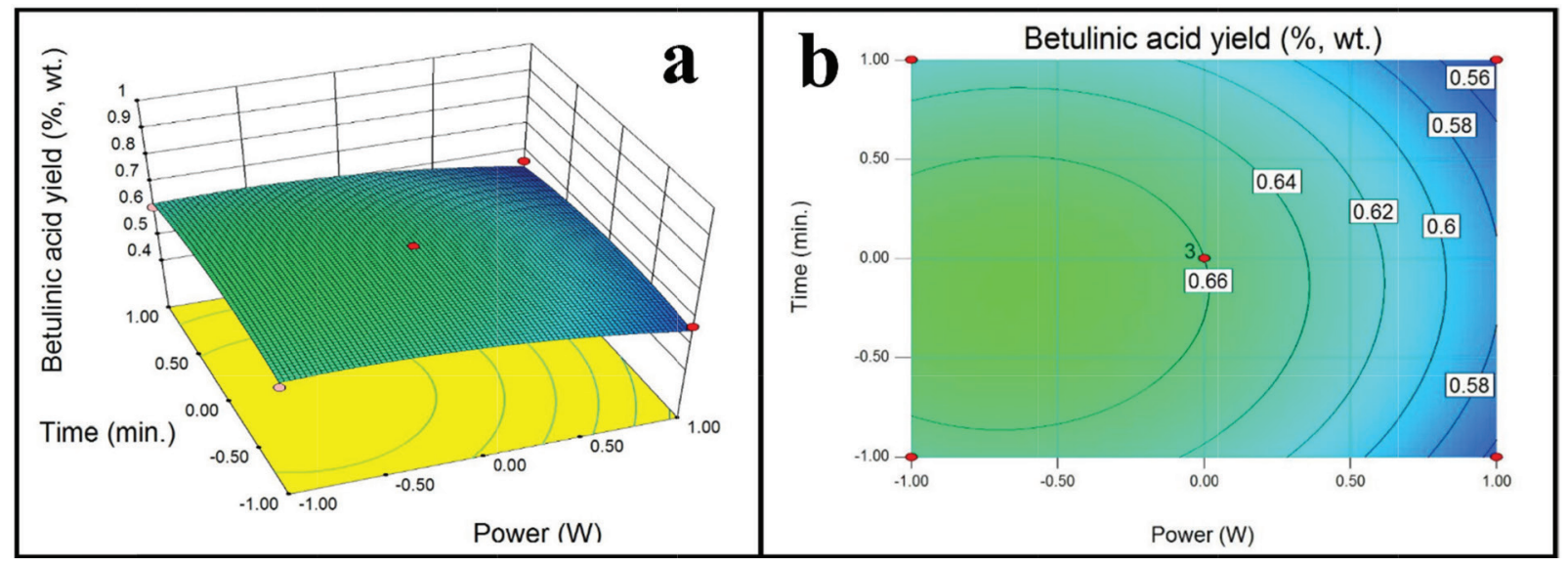

Figure 4. Effect of microwave power and extraction time on percentage yield of BA by MAE. (a) Response surface plot and (b) Contour plot.

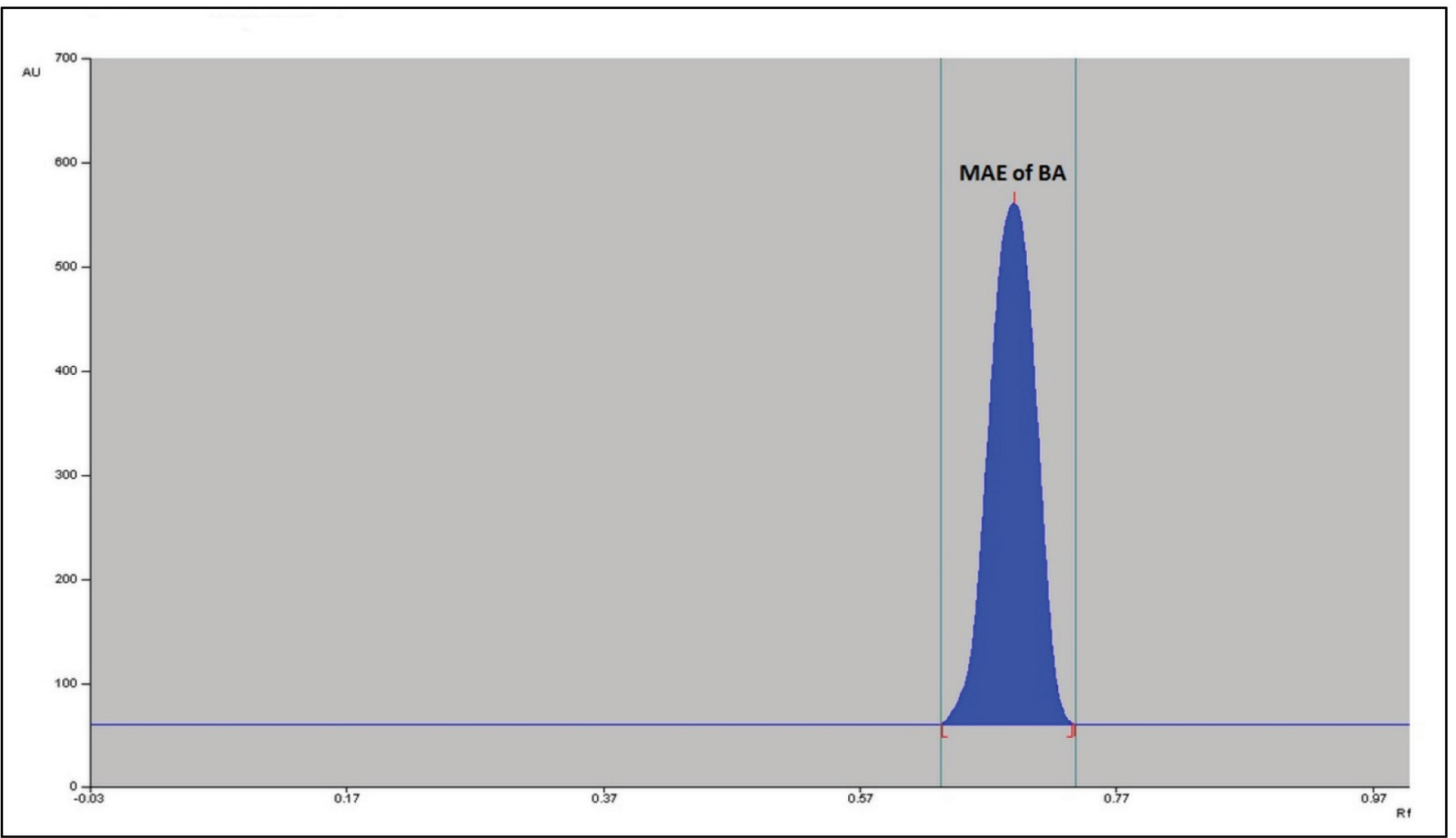

Figure 5. HPTLC chromatogram of Microwave assisted extract of BA at optimized condition $\left(R_{\mathrm{f}} 0.70\right)$. 


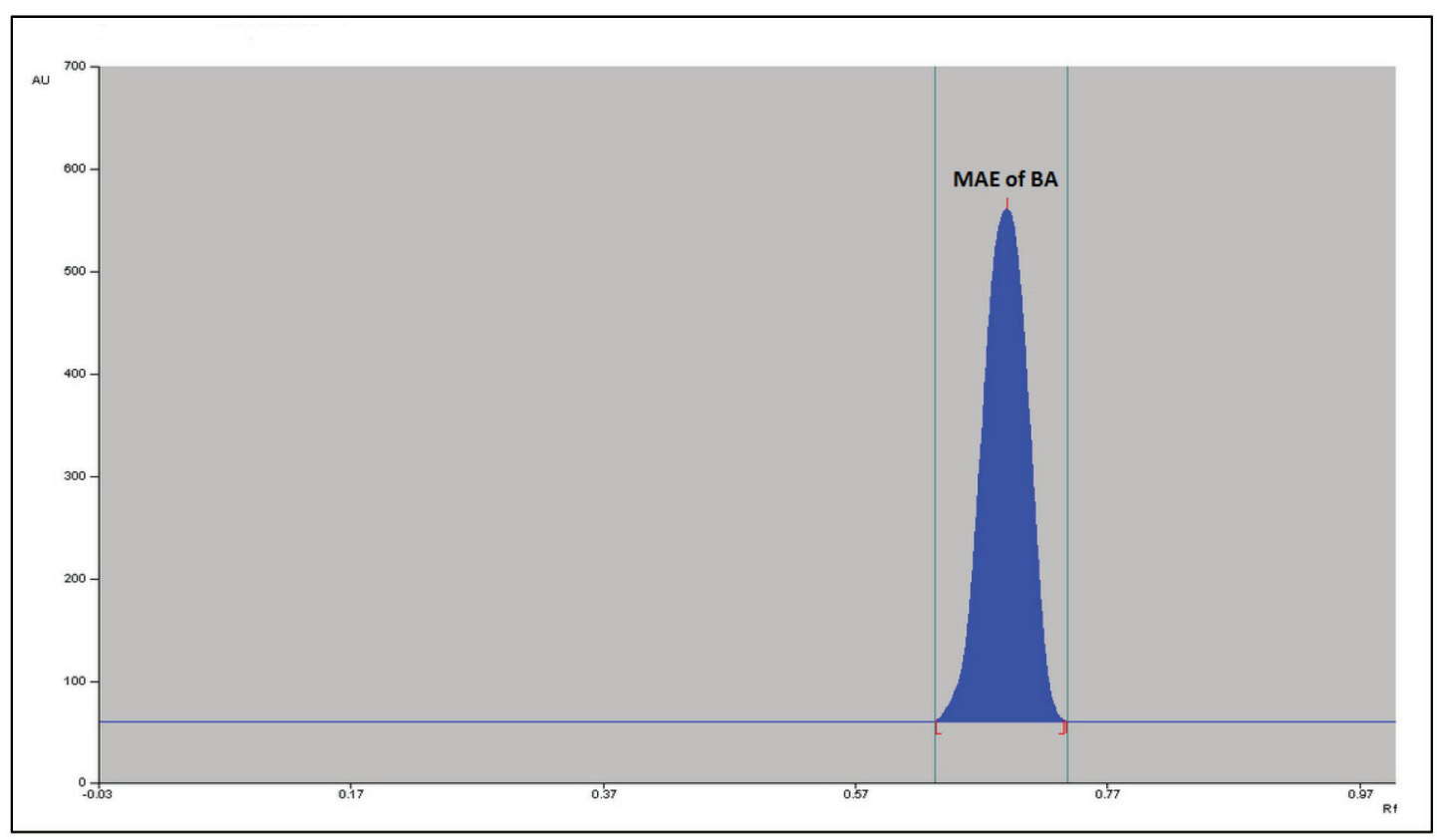

Figure 6. HPTLC chromatogram of standard BA $\left(R_{\mathrm{f}} 0.70\right)$.

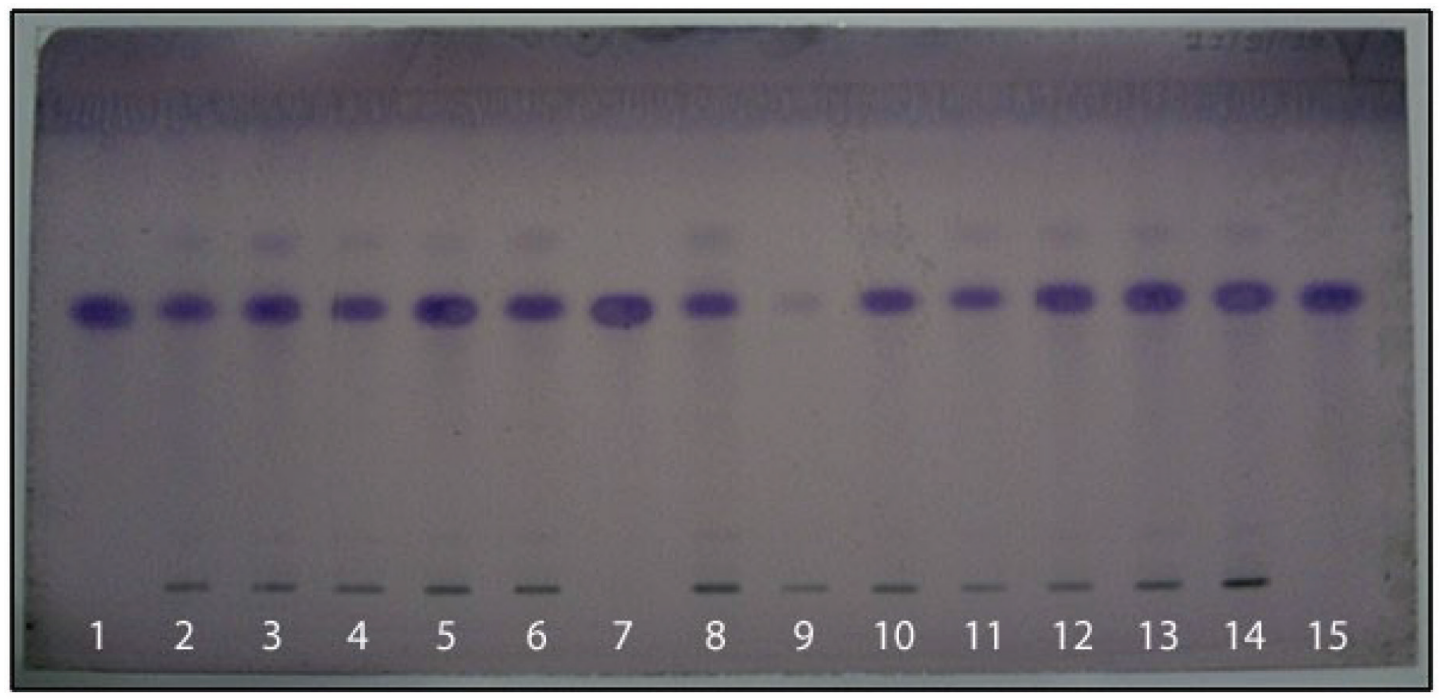

Figure 7. Derivatized HPTLC plate showing BA obtained by MAE.

et al., 2009; Li et al., 2010; Mandal et al., 2007). Therefore, BA extraction efficiency was increased with increasing temperature which is depicted in Figure 8. The maximum yield of betulinic acid was obtained at $90^{\circ} \mathrm{C}$ (Fig. 8).

\section{Effect of power on extraction yield}

Microwave power is directly proportional to the quantity of the sample and the extraction time required. The power behaves as major driving force for MAE which ruptures the plant cells and release substance from matrix which easily gets dissolved in the solvent. Therefore, increasing the power ruptures the plant cells easily which releases the phytoconstituent faster and result in shorter extraction time (Chemat et al., 2005; Hu et al., 2008; Xiao et al., 2008). The good extraction yield was obtained at $100 \mathrm{~W}$ in case of betulinic acid. Figure 9 indicates that the increase in a power greater than 100 leads to a detrimental effect on $\%$ yield, so this indicates that it does not show a linear effect on the yield with increase power. Study has been carried out to get optimum yield of BA in the research work and no study has been carried out on structural changes with temperature. The FT-IR spectra of the isolated BA obtained at the end of experiment and compared with standard betulinic acid which shows no changes in the structure of BA.

\section{Effect of time on extraction yield}

On the basis of $\%$ yield found in all the conditions, the optimal condition of time was found to be 15 minutes for maximum extraction yield. Time more than 15 minutes showed a detrimental effect on extraction yield since the methanol heat up tremendously on long exposure (Fig. 10). Extraction times in MAE is very less compared to conventional extraction 


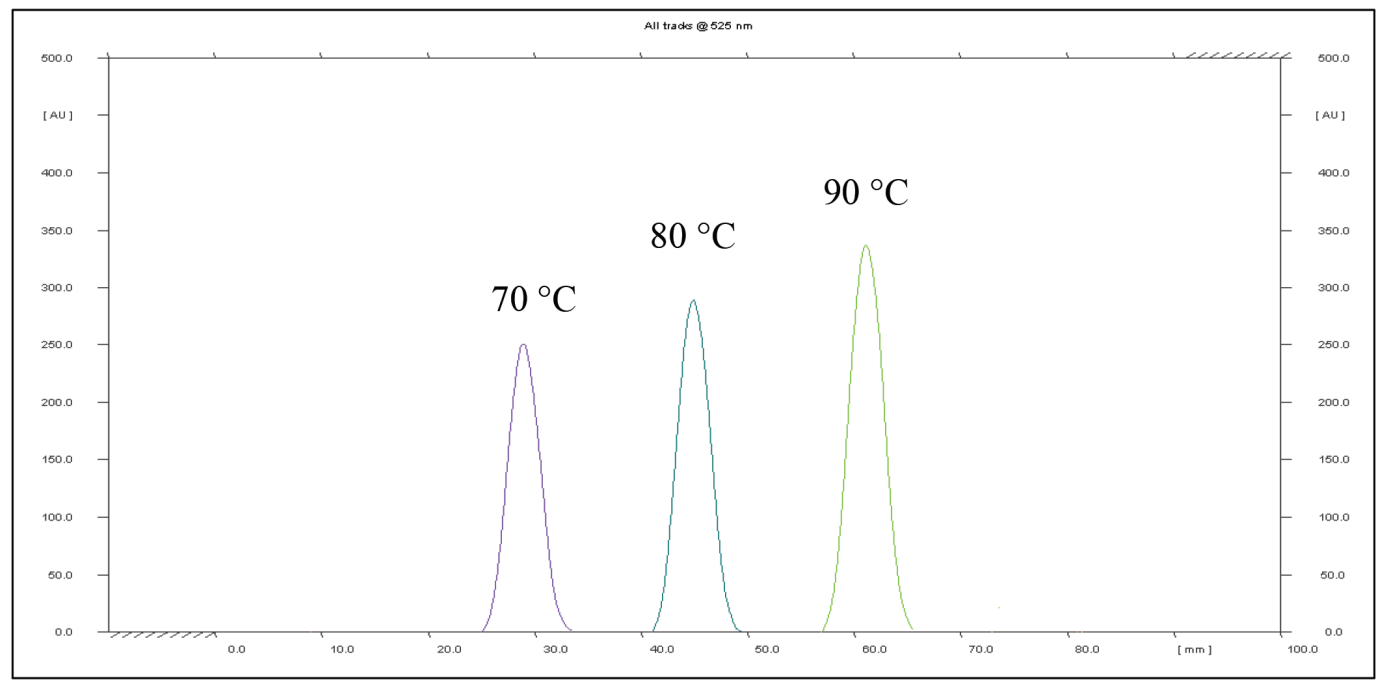

Figure 8. HPTLC densitometric chromatogram of BA at different temperature in MAE at $200 \mathrm{~W}$ and 15 minutes.

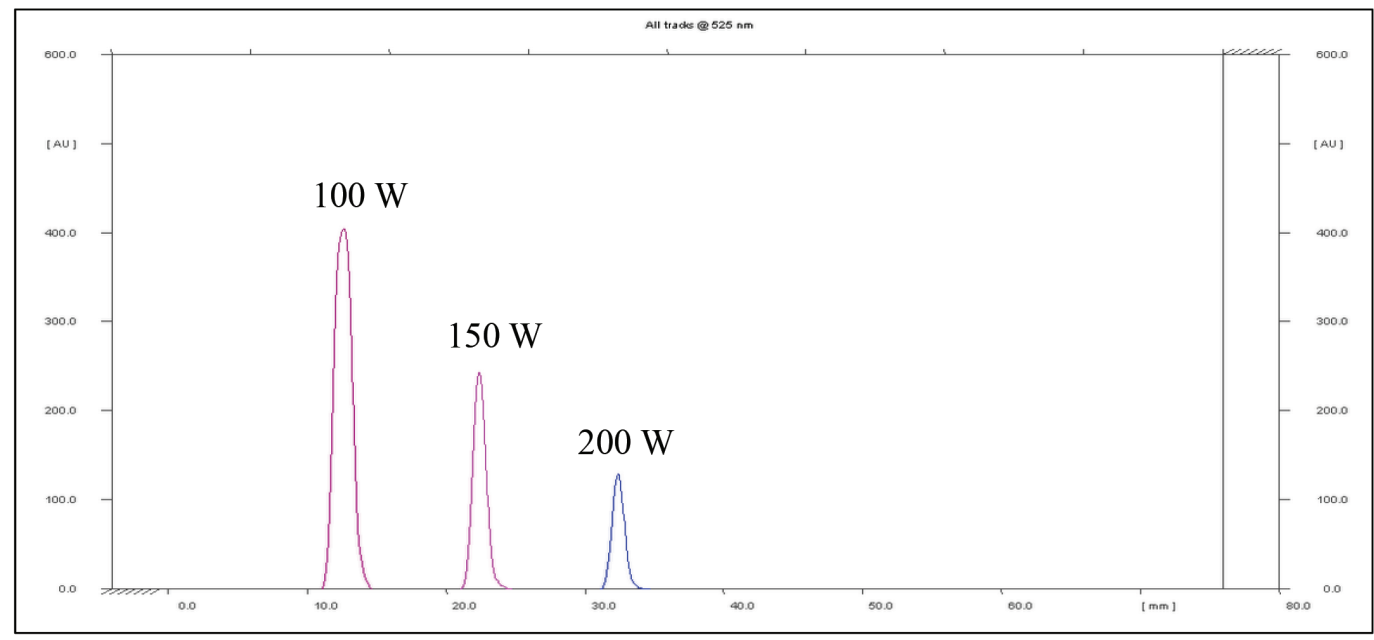

Figure 9. HPTLC densitometric chromatogram of BA at different power in MAE with $90^{\circ} \mathrm{C}$ and 15 minutes.

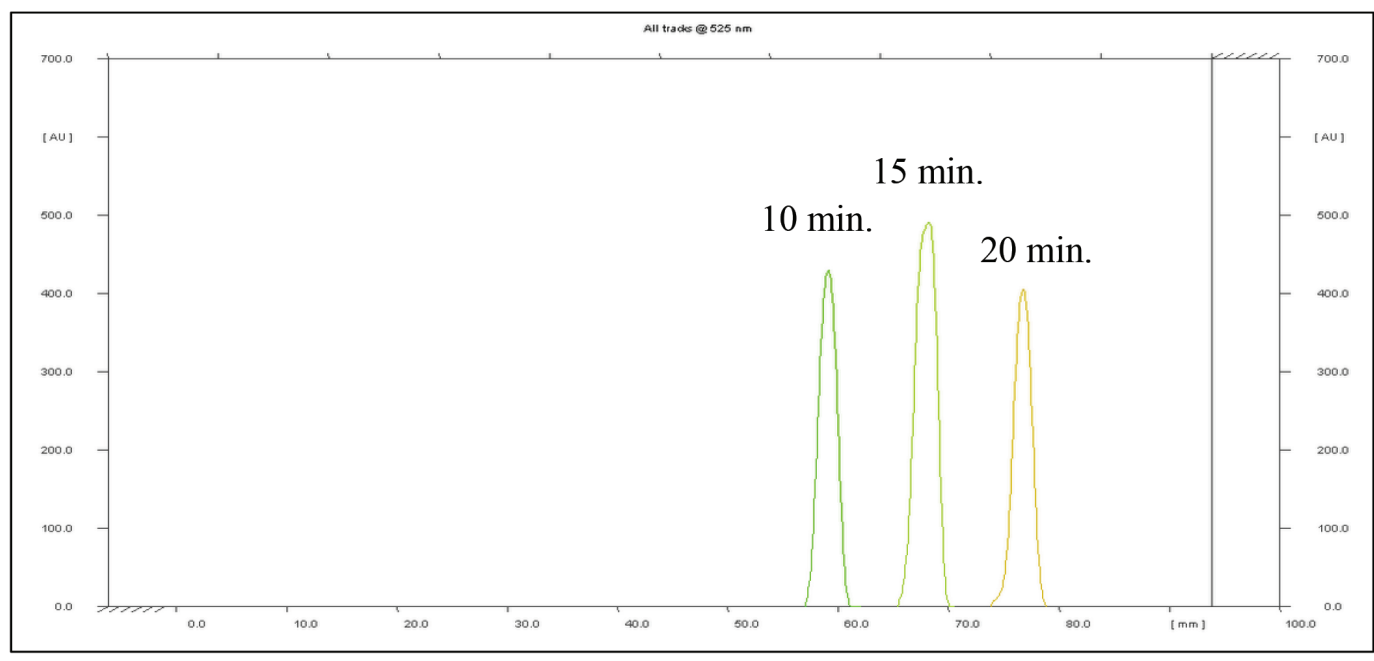

Figure 10. HPTLC densitometric chromatogram of BA at different time in MAE with $90^{\circ} \mathrm{C}$ and $100 \mathrm{~W}$. 
techniques, this usually vary from 1-3 minutes to around 30 minutes. For heat sensitive bio-actives, it is essential to check for possible thermal degradation and oxidation because of overheating of the solute-solvent system (Chan et al., 2011, Jain et al., 2009). In order to overcome overheating in solvents, such as ethanol and methanol (because of the high dielectric properties of the solvent), further dilution with water improves the heat capacity of the solvent combination (Routray, 2011). In present research, 15 minutes extraction time was found to be optimum to get good yield of betulinic acid (Wang et al., 2008).

\section{Optimized conditions of MAE for isolation of BA}

Amount of betulinic acid was calculated. It was observed from the reported data that the highest yield was obtained by extracting bark powder for 15 minutes at $90^{\circ} \mathrm{C}$, keeping $100 \mathrm{~W}$ microwave power. MAE method was applied out at optimized parameters and further used for extraction of betulinic acid (Table 3).

\section{Percentage yield and reproducibility of betulinic acid using} MAE

MAE fractions were checked for reproducibility of the optimized extraction procedure (Fig. 11). From the reported data, it has been observed that the developed MAE method is found to be reproducible (Table 4).

Table 3. HPTLC results of BA using MAE.

\begin{tabular}{clcc}
\hline SR. No. & Betulinic acid & $R_{f}$ & Area \\
\hline 1 & Microwave assisted fraction containing BA & 0.71 & 18,800 \\
2 & Standard BA (1,000 ng/spot) & 0.70 & 12,500 \\
\hline
\end{tabular}

\section{Comparison of FT-IR spectra of isolated BA and BA procured from the market}

FT-IR spectroscopy was performed to determine and confirm the functional groups of isolated BA. FT-IR spectrum of isolated compound and standard betulinic acid were recorded in diffused reflectance mode. The FT-IR spectrum of isolated bioactive presents dominant IR absorption bands at $3,456 \mathrm{~cm}^{-1}$ and $2,939 \mathrm{~cm}^{-1}$ which corresponds to $-\mathrm{OH},-\mathrm{CH}_{3}$, and $-\mathrm{CH}_{2}$ and observed asymmetric and symmetric stretching vibrations, respectively.

In finger print region, the FT-IR spectrum presents dominant bands at 1,679, 1,445, 1,368, 1,035, 885, and $792 \mathrm{~cm}^{-1}$ and many other bands of medium-to-weak intensity. The observed band at $1,679 \mathrm{~cm}^{-1}$ is related of $\mathrm{C}=\mathrm{O}$ stretching of $-\mathrm{COOH}$ functional group. Other bands in the spectral range attributed to bending vibrations of $-\mathrm{OH},-\mathrm{CH}_{2}$, and $\mathrm{CH}_{3}$ groups as well as to skeletal bending bonds. The frequency of FT-IR spectra at 1,368 $\mathrm{cm}^{-1}$ is due to $\mathrm{C}-\mathrm{O}$ stretching and the vibration of the $\mathrm{CH}_{2}$ in alkene group observed at $885 \mathrm{~cm}^{-1}$ represents. Theoretical wave numbers responsible for functional groups are compared with observed wave numbers and frequencies mentioned in Table 5 (Falamaş, 2011; Kovac-Besovic et al., 2009) (Figs. 12 and 13).

Table 4. Reproducibility of BA obtained using MAE,

\begin{tabular}{cccccc}
\hline Run & $\begin{array}{c}\text { Extraction } \\
\text { temperature }\left({ }^{\circ} \mathrm{C}\right)\end{array}$ & $\begin{array}{c}\text { Microwave } \\
\text { power }(\mathrm{W})\end{array}$ & $\begin{array}{c}\text { Extraction } \\
\text { Time (minute) }\end{array}$ & \%w/w & \% RSD \\
\hline 1 & 90 & 100 & 15 & 0.88 & 2.35 \\
2 & 90 & 100 & 15 & 0.91 & \\
3 & 90 & 100 & 15 & 0.92 & \\
\hline
\end{tabular}

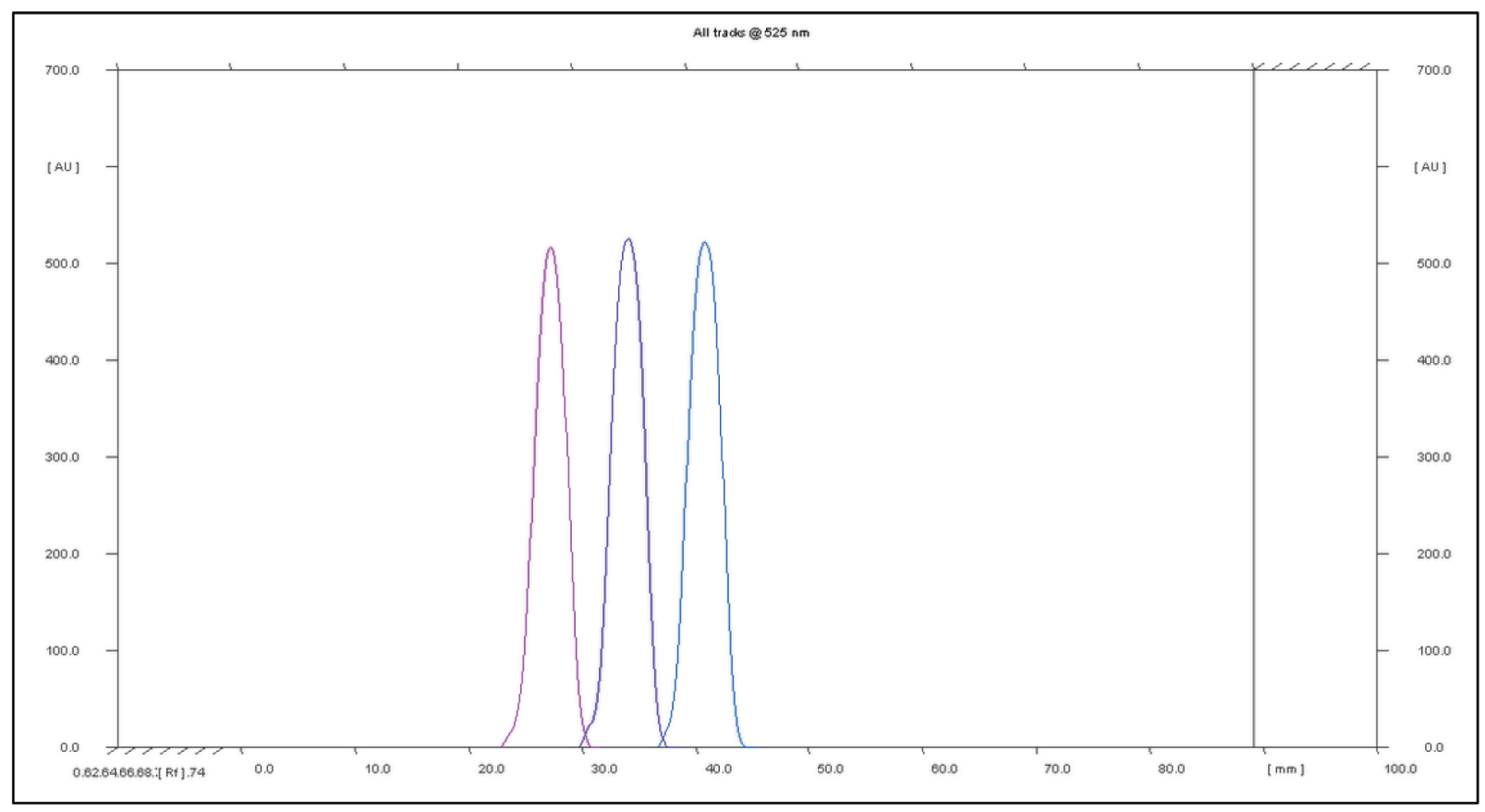

Figure 11. HPTLC densitometric chromatogram showing reproducibility of BA using MAE. 
Table 5. Important frequencies of isolated betulinic acid compared with standard BAFT-IR spectra.

\begin{tabular}{ccll}
\hline Compound parameter & $\begin{array}{c}\text { Recoded frequency of Isolated } \\
\text { BA }\left(\mathbf{c m}^{-1}\right)\end{array}$ & $\begin{array}{c}\text { Recoded frequency of } \\
\text { Standard BA }\end{array}$ & Functional group \\
\hline IR $\left(\mathrm{cm}^{-1}\right)$ & $3,459.67$ & $3,433.64$ & O-H stretching \\
& $2,939.95$ & $2,941.88$ & C-H stretching of aliphatic compounds \\
& 1,679 & $1,686.44$ & C $=\mathrm{O}$ stretch of - $\mathrm{COOH}$ group \\
& 1,455 & $1,454.06$ & OH bending \\
& 1,139 & $1,369.21,1,037.52$ & C-O stretching of -COOH group \\
\hline
\end{tabular}

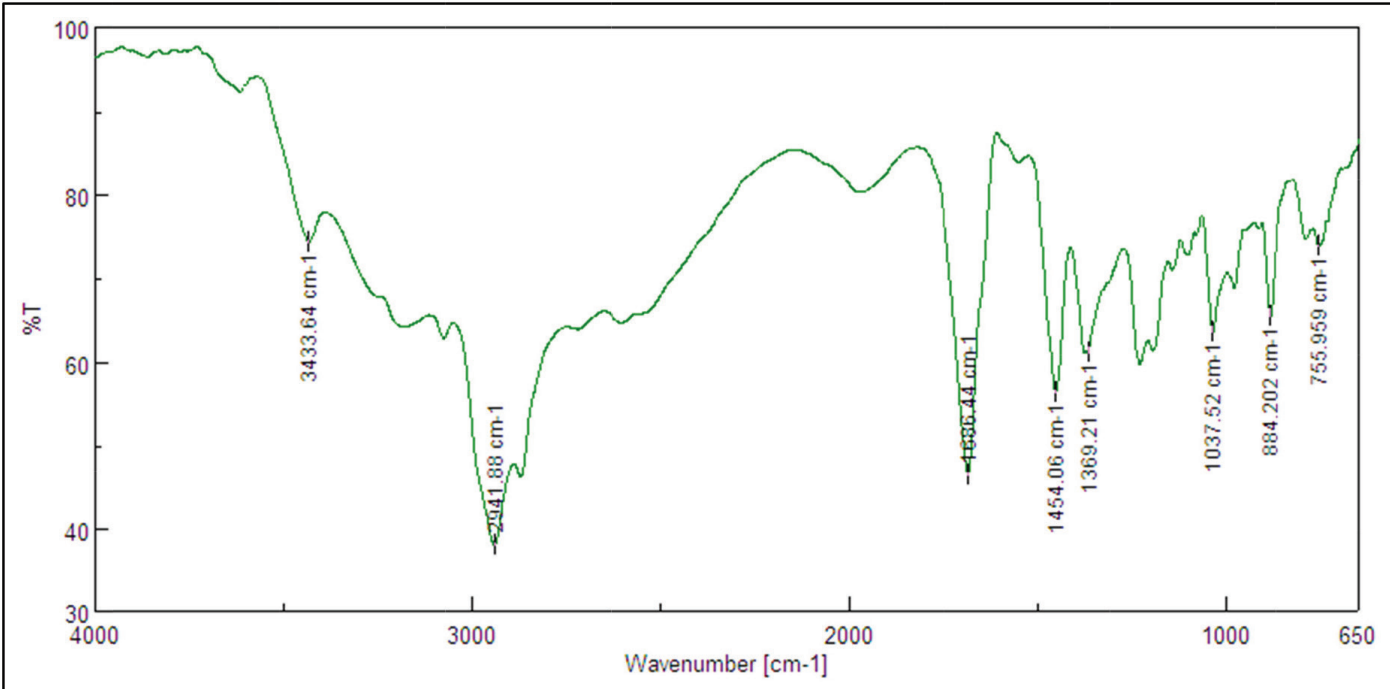

Figure 12. FT-IR spectra of isolated BA from $D$. indica bark.

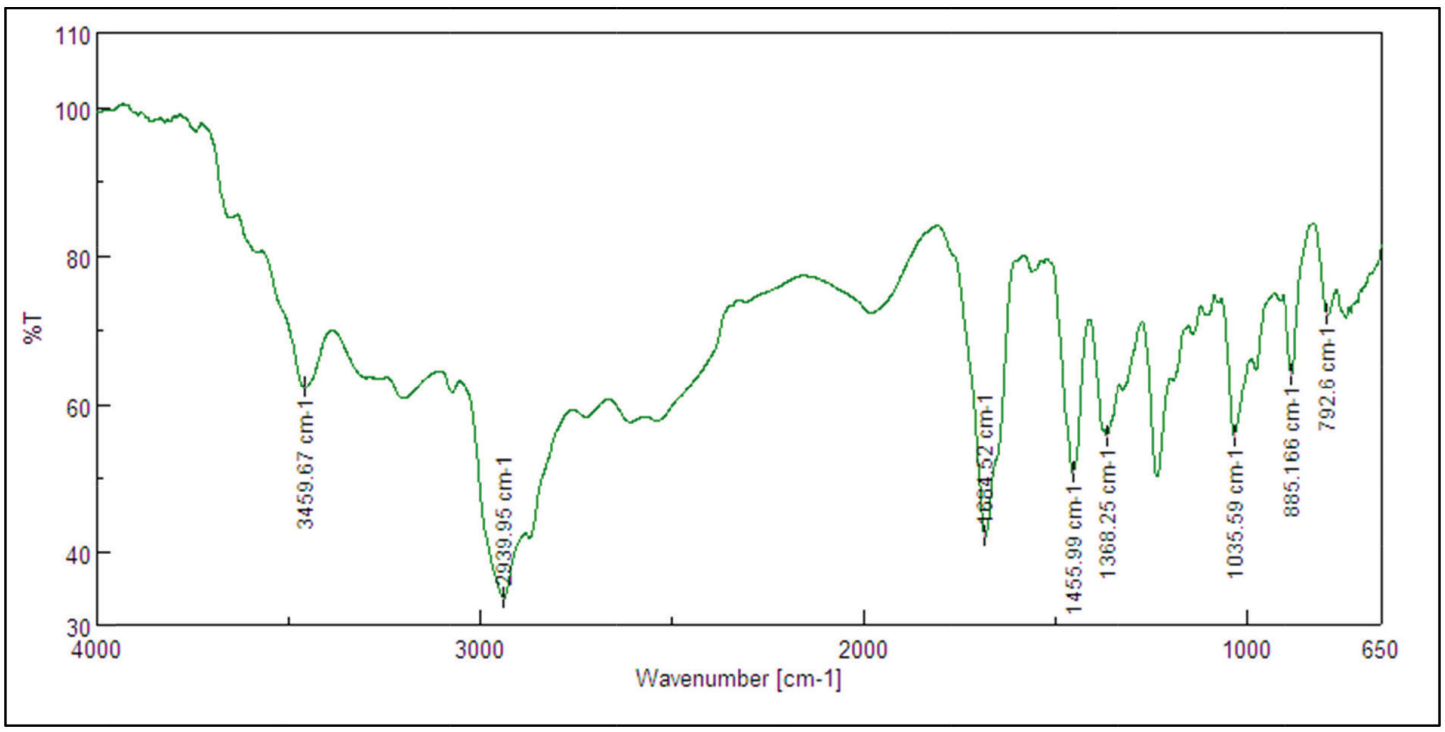

Figure 13. FT-IR spectra of BA standard.

\section{CONCLUSION}

In the present study, betulinic acid was isolated using a modern extraction method MAE and various parameters were optimized to rise the yield of BA from $D$. indica bark. The effects and interaction of MAE parameters can be optimized using
RSM to enhance the extraction efficiency. The application of chemometric tools in the optimization of methods also reduces the number of experiments, reagent consumption, and tedious laboratory work. Application of MAE for betulinic acid found to be a promising technique to reduce the lengthy process like column 
chromatography, soxhlet extraction and other conventional methods for isolation of the active constituent. In the present experiment, the significant effect on percentage yield was obtained using various temperatures, while power and time showed minimal effect. In the study proves that MAE found to be promising technique for extraction and isolation of BA from $D$. indica bark and can be extended for the isolation of many important pharmacologically active phytoconstituents from many other plants.

\section{REFERENCES}

Belwal T, Ezzat SM, Rastrelli L, Bhatt ID, Daglia M, Baldi A, Devkota HP, Orhan IE, Patra JK, Das G, Anandharamakrishnan C. A critical analysis of extraction techniques used for botanicals: trends, priorities, industrial uses and optimization strategies. TrAC Trend Anal Chem, 2018; 100:82-102.

Chan CH, Yusoff R, Ngoh GC, Kung FWL. Microwave-assisted extractions of active ingredients from plants. J Chromatogr A, 2011; 1218(37):6213-25.

Chemat S, Ait-Amar H, Lagha A, Esveld DC. Microwaveassisted extraction kinetics of terpenes from caraway seeds. Chem Eng Process, 2005; 44(12):1320-6.

Cichewicz RH, Kouzi SA. Chemistry, biological activity and chemotherapeutic potential of betulinic acid for the prevention and treatment of cancer and HIV infection. Med Res Rev, 2004; 24:90-114.

Cristina A, Dehelean CS, Ledeţi I, Aluaş M, Zupko I, Galuşcan A, Cinta-Pinzaru S, Munteanu M. Study of the betulin enriched birch bark extracts effects on human carcinoma cells and ear inflammation. Chem Cent J, 2012; 6:137.

Daneshvand B, Ara MK, Raofie F. Comparison of supercritical fluid extraction and ultrasound-assisted extraction of fatty acids from quince (Cydonia oblonga Miller) seed using response surface methodology and central composite design. J Chromatogr A, 2012; 1252:1-7.

Deng B, Liu Z, and Zou Z, Optimization of microwave-assisted extraction saponins from Sapindus mukorossi Pericarps and an evaluation of their inhibitory activity on Xanthine Oxidase. JChem, 2019; 2019:11.

Domingues RMA, Demelo MMR, Oliveira ELG, Neto CP, Silvestre AJD, Silva CM. Optimization of the supercritical fluid extraction of triterpenic acids from Eucalyptus globulus bark using experimental design. J Supercrit Fluids, 2013; 74:105-14.

Eskilsson CS, Bjorklund E. Analytical-scale microwave-assisted extraction. J Chromatogr A, 2000; 902(1):227-50.

Falamaş A, Pinzaru SC, Dehelean CA, Peev CI, Soica C. Betulin and its natural resource as potential anticancer drug candidate seen by FTRaman and FT-IR spectroscopy. J Raman Spectrosc, 2011; 42: 97-107.

Ferreira SL; Bruns RE, Ferreira HS. Box-Behnken design: an alternative for the optimization of analytical methods. Anal Chim Acta, 2007; 597:179-86.

Galgon T, Hoke D, Drager B. Identification and quantification of betulinic acid. Phytochem Anal, 1999; 10:187-90.

Gandhi D, Mehta P. Dillenia indica Linn. and Dillenia pentagyna Roxb.: pharmacognostic, phytochemical and therapeutic aspects. J App Pharm Sci, 2013b; 3(12):134-42.

Gandhi DM, Mehta PJ. Validated high-performance thin-layer chromatographic method for the quantification of betulinic acid from two Indian plants of the species Dillenia and Ziziphus. J Planar Chromatogr, 2013a; 26:331-5.

Gava FA, Szarka S, Simandi B, Blazics B, Simon B, Kery A. Supercritical fluid extraction of Alnus glutinosa (L.) Gaertn. J Supercrit Fluids, 2012; 61:55-61.

Habiyaremye I, Stevanovic-Janezic T, Riedl B, François-Xavier, Garneau F-IJ. Pentacyclic triterpene constituents of yellow birch bark from Quebec. J Wood Chem Technol, 2002; 22:83-91.
$\mathrm{Hu}$ Z, Cai M, Liang HH. Desirability function approach for the optimization of microwave-assisted extraction of saikosaponins from Radix bupleuri. Sep Purif Technol, 2008; 61(3):266-75.

Jain T, Jain V, Pandey R, Vyas A, Shukla SS. Microwave assisted extraction for phytoconstituents-an overview. Asian J Res Chem, 2009; 2(1):19-25.

Khajeh M, Akbari MAR, Sanchooli E. Application of Doehlert design in the optimization of microwave-assisted extraction for determination of zinc and copper in cereal samples using FAAS. Food Anal Methods, 2010; 3(3):133-7.

Kovac-Besovic E, Duric K, Kalodera Z, Sofic E. Identification and isolation of pharmacologically active triterpenes in Betuale cortex, Betula pendula Roth., Betulaceae. Bosn J Basic Med Sci, 2009; 9(1):32-8.

Kumar D, Mallick S, Vedasiromoni RJ, Pal CB. Anti-leukemic activity of Dillenia indica L. fruit extract and quantification of betulinic acid by HPLC. Phytomedicine, 2010; 17:431-5.

Li J, Zu YG, Fu YJ, Yang YC, Li SM, Li ZN. Optimization of microwave-assisted extraction of triterpene saponins from defatted residue of yellow horn (Xanthoceras sorbifolia Bunge.) kernel and evaluation of its antioxidant activity. Innov Food Sci Emerg Technol, 2010; 11(4):637-43.

Liu Y-H, Yan E, Zhan H-Y, Zhang Z-Q, Response surface optimization of microwave-assisted extraction for HPLC-fluorescence determination of puerarin and daidzein in Radix Puerariae thomsonii. J Pharm Anal, 2011; 1(1):13-9.

Mandal V, Mohan Y, Hemalath S. Microwave-assisted extraction - an innovative and promising extraction tool for medicinal plant research. Pharmacogn Rev, 2007; 1(1):7-18.

Moghaddam MG, Ahmad FBH, Samzadeh-kermani A. Biological activity of betulinic acid : a review. Pharmacol Pharm, 2012; 119-23.

Muhit MA, Tareq SM, Apu AS, Basak D, Islam MS. Isolation and identification of compounds from the leaf extract of Dillenia indica Linn. Bangladesh Pharm J, 2010; 13:49-53.

Mullauer FB, Kessler JH, Medema JP. Betulinic acid, a natural compound with potent anticancer effects. Anticancer Drugs, 2010; 21 : $215-27$

Pai RS, Nimbalkar SM, Pawar VN, Dixit BG. Optimization of extraction techniques and quantification of Betulinic Acid (BA) by RPHPLC method from Ancistrocladus heyneanus Wall. Ex Grah. Ind Crops Prod, 2011; 34:1458-64.

Routray W, Orsat V. Microwave-assisted extraction of flavonoids: a review. Food Bioprocess Technol, 2012; 5(2):409-24.

Sladkova A, Stopka J, Haz A, Strizincova P, Surina I, Kreps F, Burcova Z, Jablonsky M. Microwave-assisted extraction of spruce bark: statistical optimization using Box-Behnken design. BioResources, 2018, 13(4):8993-9004

Tatke, P., and Y. Jaiswal. An overview of microwave assisted extraction and its applications in herbal drug research. Res J Med Plant 2011; 5(1):21-31.

Wang Y, You J, Yu Y, Qu C, Zhang H Ding, L. Analysis of ginsenosides in Panax ginseng in high pressure microwave-assisted extraction. Food Chem, 2008; 110(1):161-7.

Xiao W, Han L, Shi B. Microwave-assisted extraction of flavonoids from Radix astragali. Sep Purif Technol, 2008; 61(3):614-8.

How to cite this article:

Gandhi DM, Patel H, Patel N, Mehta P. Optimization of microwave-assisted extraction technique for isolation of betulinic acid from Dillenia indica Linn. and its quantification using developed HPTLC method. J Appl Pharm Sci, 2019; 9(08):101-110. 